\title{
Response of Bone Collagen and Connexin-43 to an Aquatic Training Program.
}

\section{Ayat Y. Bagato}

Lecturer in Biological sciences and sport health department, Faculty of physical education for girls, Helwan University.

\begin{abstract}
Exercise can increase bone mass by maintaining adequate balance between bone formation and resorption. Bone cells coordinate their responses to mechanical load by communicating via gap junctions connexons. There is no previous studies have compared the acute response of bone markers to chronic response with regard to gap junction. Aim of this study was to examine the acute response of bone markers post-exercise to pre-exercise and chronic response (adaptation) to training program. Plasma $C$ terminal of type I procollagen (CICP) (marker for bone formation), enzyme serum band 5 tartarate resistant acid phosphatase (TRAP 5b) (marker of bone resorption) and connexin 43 (gap junction response) were assayed and compared to bone response. Methods: 15 adult sedentary females participated in an aquatic training program for 4 months aged $50.21 \pm 3.07$ years. Their physical characteristics and bone markers were measured pre and post-exercise before and after the program. Body composition results revealed significant variation in all parameters after program compared to that obtained before program except for percent body fat $(p<0.001)$. Bone markers results indicated no significant variations in the blood levels of TRAP b5 and connexin 43 before program compared to that obtained after program either at rest (Preexercise) or after exercise (post-exercise) but was significant for CICP only in pre-exercise after the program $(p<0.04)$. Pre-exercise compared to post-exercise either before or after program were significant in the all three investigated bone parameters $(p<0.01)$. Results: The results indicated that bone functional adaptation is continued until the skeletal design meets the loading requirements. Post-exercise results seem to be related to the timing of the measurement of bone turnover markers relative to the last exercise bout or the diurnal variation of bone resorption markers. Conclusions: It is concluded that the changes in CICP observed following the training program indicates increased bone formation with stable resorption with net bone increase in bone mass. In addition, connexin-43 increases cell-tocell response to exercise training program leading to adaptation in all muscloskeletal system. .
\end{abstract}

Key words: Mechanotransduction- Type I procollagen (CICP) - Connexin 43 (Cx43) Tartarate resistant acid phosphatase (TRAP 5b) - Aquatic training program.

Introduction:

$\mathrm{E}$ xercise can increase bone mass, whereas exposure to a microgravity environment) can induce bone loss. Although it is well accepted that mechanical signals are critical to maintain an adequate skeleton, the mechanism by which bone cells sense their mechanical environment and initiate the deposition or resorption of bone tissue has not been ascertained completely (Fritton and Weinbaum, 2009). 
Exercise presumably increases bone mass by altering the balance between bone formation and resorption, such that there is a net gain. However, exercise interventions that increase bone mass do not always result in detectable changes in serum bone formation or resorption markers from pre- to postintervention (Rogers et al., 2011). Babraj et al. (2005) reported that the extracellular matrix of skeletal muscle, tendon, ligament, and bone is important for maintaining tissue structure and vital for transmission of force during muscular contraction (15). Collagen is the major protein in the extracellular matrix of the musculoskeletal tissue, but despite its importance to tissue function, knowledge of the physiological regulation of the amount and turnover of collagen in human beings is poor. Haus et al. (2007) hypothized that a critical component in the transfer of force from the contractile units of the muscle out to the tendon and subsequent bone is the connective tissue scaffold that surrounds individual muscle fibers, muscle bundles, and the whole muscle (Huijing, 1999; Kjaer , 2004). This skeletal muscle connective tissue network is primarily composed of collagen fibers and biochemical linkages within and between these fibers, which provide strength and stability.

The question arises is how bone response and adapt to an exercise program with its very low innervations. Much recent evidence suggests that bone cells sense their mechanical environment via interstitial fluid flow (Fritton and Weinbaum, 2009). Cells coordinate their responses to mechanical load by communicating via gap junctions .A gap junction is a group of ion channels (connexons) through which molecules of less than 1000 molecular weight pass. One level of signaling involves an increase in intracellular calcium in mechanically stimulated cells, whose wave is thought to be propagated from cell to cell through gap junctions (Wang and Tian, 2009). Intercellular channels gap junctions are composed of two hexameric oligomers called connexons or hemichannels, with one each contributed by contacting cells (Koval, 2006; Laird, 2006). The gap junctions protein connexin $43(\mathrm{Cx} 43)$ is the most ubiquitous connexin responsible for intercellular mechanotransduction.

Mechanotransduction refers to the process by which the body converts mechanical loading into cellular responses. These cellular responses, in turn, promote structural change. A classic example of mechanotransduction in action is bone adapting to load. A small, relatively weak bone can become larger and stronger in response to the appropriate load through the process of mechanotransduction (Scott et al., 2011).

To the best of our knowledge, no previous studies have compared the acute response of bone markers to chronic response with regard to gap junction functional protein connexin 43. Therefore, the overall objective of the present study, which included two measures (before and after) training program, was to examine the acute response of bone markers post-exercise to pre-exercise and chronic response (adaptation) to training program. Plasma C terminal of type I procollagen (CICP) (marker for bone formation), enzyme serum band 5 tartarate resistant acid phosphatase (TRAP 5b) (marker of bone resorption) and connexin 43 (gap junction response) are assayed and related to bone response.

\section{Material and Methods:}

\section{Subjects:}

15 adult sedentary females participated in an aquatic training program for four months in 
this study on the swimming department in the Faculty of physical education for girls at Helwan University in Giza. The subjects voluntarily provided written informed consent before participating. There was no clinical or analytical evidence for any disease among the participants. Participants aged $50.21 \pm 3.07$ years, height $162.21 \pm 5.44 \mathrm{~cm}$. and weight at the start of the program 88.01 $\pm 14.67 \mathrm{k}$. They were subjected to a graded training program for four months in a legal basin.

\section{Study design:}

The participants underwent 3 sessionslweek for 4 months which classified as four moderate to intensive exercise units in every training session. Each unit consisted of warm-up followed by aerobic exercises, resistance exercises and flexibility exercises. The training program was summarized in table (1).

(Table 1)

Training program graded through four months

\begin{tabular}{|c|c|c|c|c|c|}
\hline Month & \multicolumn{5}{|c|}{ Training session } \\
\hline & $\begin{array}{c}\text { Intensity } \\
(\text { vo2max })\end{array}$ & Warm-up & Aerobic exercises & Resistance exercises & $\begin{array}{c}\text { Flexibilitylcalming } \\
\text { exercises }\end{array}$ \\
\hline $1^{\text {st }}$ & $\mathbf{5 0 \%}$ & $20 \mathrm{~min}$ & $15 \mathrm{~min}$ & $15 \mathrm{~min}$ & $10 \mathrm{~min}$ \\
\hline $2^{\text {nd }}$ & $\mathbf{6 0 \%}$ & $20 \mathrm{~min}$ & $15 \mathrm{~min}$ & $15 \mathrm{~min}$ & $10 \mathrm{~min}$ \\
\hline $3^{\text {rd }}$ & $\mathbf{7 0 \%}$ & $\mathbf{2 0} \mathrm{min}$ & $15 \mathrm{~min}$ & $15 \mathrm{~min}$ & $10 \mathrm{~min}$ \\
\hline $4^{\text {th }}$ & $\mathbf{8 0} \%$ & $\mathbf{2 0} \mathrm{min}$ & $15 \mathrm{~min}$ & $15 \mathrm{~min}$ & $10 \mathrm{~min}$ \\
\hline
\end{tabular}

\section{Physical Studies:}

Body composition analyzer ( In Body) was used to measure participants body for skeletal muscle mass in $\mathrm{kg}$ (SMM), fat mass in $\mathrm{kg}$, free fat mass in $\mathrm{kg}$ (FFM), percent body fat (PBF), waist/hip ratio (WHR) and basal metabolic rate in calories (BMR). Measurements were recorded before and after the training program.

\section{Blood analysis:}

Blood samples at rest were collected under aseptic conditions from the anti-cubital vein. Post-exercise blood sampling was performed immediately after the exercise unit. Venous samples for the measurement of plasma parameters were collected in tubes containing EDTA in the morning after fasting, after resting for at least 30 minutes and immediately after exercise, centrifuged and kept at $-20 \mathrm{C}^{\mathrm{o}}$ until tested. $\mathrm{C}$ terminal type I procollagen, TRAP $5 \mathrm{~b}$ and connexin 43 levels were determined using a commercial ELISA kits provided by Teco medical group, Germany.

\section{Statistical analysis:}

All data are reported as mean \pm standard deviation (SD). The SPSS 17 software program was used to execute all statistical analyses. The paired sample t-test was used to compare the means of each group before and after the training program. All of the data were correlated to exercise. The level of significance was set at $\mathrm{p} \leq 0.05$.

\section{Results}

Body composition results revealed significant variation in all parameters after 
program compared to that obtained before program except for pure body fat which indicates there is still fat deposition requires more burning to be lost. Table (2) represents results of these physical parameters

(Table 2)

Body composition for investigated female subjects before aquatic training program compared to after program

\begin{tabular}{|c|c|c|c|c|c|}
\hline & Before & After & $\mathbf{t}$ & $\mathbf{P}$ & Sig \\
\hline Weight & $88.01 \pm 14.67$ & $80.47 \pm 11.16$ & 6.32 & $<0.001$ & $\mathbf{S}$ \\
\hline SMM & $27.97 \pm 5.44$ & $29.45 \pm 5.56$ & -8.55 & $<0.01$ & $\mathbf{S}$ \\
\hline Fat mass & $37.26 \pm 13.02$ & $33.04 \pm 10.7$ & 4.37 & $<0.001$ & $\mathbf{S}$ \\
\hline FFM & $50.75 \pm 9.98$ & $47.42 \pm 7.96$ & 3.52 & $<0.01$ & $\mathbf{S}$ \\
\hline PBF & $41.45 \pm 11.35$ & $40.46 \pm 11$ & 1.21 & $>0.25$ & NS \\
\hline WHR & $1.08 \pm 0.08$ & $1.03 \pm 0.07$ & 7.56 & $<0.001$ & $\mathbf{S}$ \\
\hline BMR & $1466.85 \pm 193.82$ & $1747.92 \pm 192.21$ & -13.47 & $<0.001$ & $\mathbf{S}$ \\
\hline
\end{tabular}

SMM: Skeletal muscle mass FFM: Free fat mass PBF: Pure fat mass (Body fat mass/weight) WHR: Wais/hip ratio

BMR: Basal metabolic rate

Revealed data results indicated no significant variations in the blood levels of TRAP b5 and connexin 43 before program compared to that obtained after program either at rest (Pre-exercise) or after exercise (postexercise) but was significant for CICP only in pre-exercise after the program (Table 3).

(Table 3)

Comparison between blood levels of TRAP b5, CICP and connexin 43 before program to after program

\begin{tabular}{|c|c|c|c|c|c|}
\hline & Before program & After program & & & \\
\hline & \multicolumn{2}{|c|}{ Pre-exercise } & $\mathbf{t}$ & $\mathbf{P}$ & Sig. \\
\hline TRAP b5 (U/L) & $2.46 \pm 0.54$ & $2.53 \pm 0.64$ & -0.22 & 0.83 & NS \\
\hline CICP(ng/ml) & $94.8 \pm 17.65$ & $114 \pm 17.37$ & -2.39 & 0.04 & $\mathbf{S}$ \\
\hline \multirow[t]{2}{*}{ connexin $43(\mathrm{ng} / \mathrm{ml})$} & $0.273 \pm 0.08$ & $0.278 \pm 0.06$ & -0.20 & 0.84 & NS \\
\hline & \multicolumn{2}{|c|}{ Post-exercise } & $\mathbf{t}$ & $\mathbf{P}$ & Sig. \\
\hline TRAP b5 & $4.05 \pm 0.44$ & $3.7 \pm 0.65$ & 1.26 & 0.24 & NS \\
\hline CICP & $151.2 \pm 21.05$ & $155.8 \pm 17.54$ & -0.53 & 0.61 & NS \\
\hline connexin 43 & $0.352 \pm 0.06$ & $0.33 \pm 0.08$ & 0.65 & 0.53 & NS \\
\hline
\end{tabular}

Reverse to obtained results of pre to post program, pre-exercise compared to postexercise either before or after program were significant in the all three investigated bone parameters as presented in table (4). 
(Table 4)

Comparison between blood levels of TRAP b5, CICP and connexin 43 pre-exercise to post-exercise

\begin{tabular}{|c|c|c|c|c|c|}
\hline & \multicolumn{2}{|c|}{ Before program } & \multirow[b]{2}{*}{$\mathbf{t}$} & \multirow[b]{2}{*}{$\mathbf{P}$} & \multirow[b]{2}{*}{ Sig. } \\
\hline & pre-exercise & post-exercise & & & \\
\hline TRAP b5 & $2.46 \pm 0.54$ & $4.05 \pm 0.44$ & -13.18 & 0.00 & $\mathbf{S}$ \\
\hline CICP & $94.8 \pm 17.65$ & $151.2 \pm 21.05$ & -19.53 & 0.00 & $\mathbf{S}$ \\
\hline \multirow[t]{3}{*}{ connexin 43} & $0.273 \pm 0.08$ & $0.352 \pm 0.06$ & -3.59 & 0.01 & $\mathbf{S}$ \\
\hline & \multicolumn{2}{|c|}{ After program } & & & \\
\hline & pre-exercise & post-exercise & $\mathbf{t}$ & $\mathbf{P}$ & Sig. \\
\hline TRAP b5 & $2.53 \pm 0.64$ & $3.7 \pm 0.65$ & -3.16 & 0.01 & $\mathbf{S}$ \\
\hline CICP & $114 \pm 17.37$ & $155.8 \pm 17.54$ & -7.94 & 0.00 & $\mathbf{S}$ \\
\hline connexin 43 & $0.278 \pm 0.06$ & $0.33 \pm 0.08$ & -7.94 & 0.00 & $\mathbf{S}$ \\
\hline
\end{tabular}

\section{Discussion}

Body composition variation indicated significant progress in fat loss due to the training program although it indicates need for more loss of fat deposition in the participant females., as they adult, their fat deposition loss is so difficult to loose.

The most important observation made in the present study was to investigate bone response and metabolism before and after training exercise program. TRAP b5 was evaluated for bone resorption, CICP for bone deposition and connexin-43 for inter bone cellular co-ordination in response to the training program. There were no significant differences observed at rest (pre-exercise) or after exercise effort (post-exerciser) in all results obtained except for CICP (Table 3) compared to themselves, which found to be elevated at rest after the training program ( $p$ $<0.04)$.

Bone is continually undergoing processes of reinforcement and resorption (bone functional adaptation) until the skeletal design meets the loading requirements. The cellular and molecular studies indicated that bone cells, i.e. osteoblasts and osteocytes, are mechanosensitive cells (Shu et al., 2011). It is proofed that dynamic tension was found to regulate both fibroblastic and osteogenic associated genes while dynamic compression up-regulated genes associated with chondrogenesis (Haudenschild et al., 2009).

Bonewald and Johnson (2008) hypothized that osteocytes appear to be reflect the strain signals and distribute them throughout the whole bone to regulate bone (re)modeling (Lanyon, 1993). Recently it has been shown that deletion of osteocytes results in bone loss and bone with deleted osteocytes does not respond to load. These studies show that osteocytes are necessary to maintain bone mass in response to normal load, but in the absence of load, they send signals of resorption (Tatsumi et al., 2007). Hence, as revealed in the present study, the net result of training program lead to bone deposition with elevated CICP as bone formation marker.

We also hypothesized that exercise would modify the acute bone response resulted in post-exercise compared to pre-exercise in all investigated parameters (Table 4). These results seem to be related to the timing of the measurement of bone turnover markers relative to the last exercise bout or the diurnal variation of bone resorption markers 
(Henriksen et al., 2003) rather than the training program effect.

Rogers et al. (2011) studied the acute response of bone formation and resorption markers including tartrate-resistant acid phosphatase 5b (TRAP 5b), $\mathrm{COOH}$ terminal telopeptide of type I collagen (CTX), to a single bout of resistance exercise or polymetric exercise. In general, they observed cumulative decreases in TRAP5b during the $2 \mathrm{~h}$ following exercise while CTX remained unchanged. Their results suggest that the timing of the measurement is important for detection of exercise-associated changes in bone turnover markers, as the markers returned to pre-exercise values within $2 \mathrm{~h}$ of exercise.

Langberg et al. (2001) found that type I collagen synthesis is accelerated in response to prolonged strenuous exercise, reaching a peak after 3 days and returning to preexercising levels 5 days after the completion of a marathon run.

Virtanen et al. (1993) reported that a single bout of heavy concentric exercise causes protein leakage from muscles and probably from the collagen-synthesizing cells of the connective tissue, which may be accompanied by an initial decrease and a subsequent increase in type I collagen production. The activation of type I collagen production seems to depend on the strain and damage of the musculoskeletal system.

Plasma connexin-43 was first to be estimated as a marker for gap junction response to a training program. Results were not significant in after program compared to before program. These results may explain under the hypothesis that it affects bone mass rather than releasing in lymphatic system.

Connexin-43 junctional conductance is activated at 70-85 $\mathrm{mV}$ which cause junctional currents, resulting in a steady-state conductance which is a fraction of the instantaneous conductance (Brink et al., 2000). Connexin enhanced fluid flow through the cannalicular system of the osteocytes so amplify the strain signals that induce increases in bone mass.

Charles and coworkers (1992) showed that loss of connexin-43 expression resulted in poor junctional competence and loss of the ability to transmit a calcium signal to a neighboring cell. Transfection of junctionally incompetent cells with connexin-43 DNA codon restored intercellular communication. Therefore, gap junctions represent one mechanism cells use to regulate a response to mechanical and chemical signals.

Thus, we concluded that the changes in CICP observed following the training program indicates increased bone formation with stable resorption with net bone increase in bone mass. In addition, connexin-43 increases cell-to-cell response to exercise training program leading to adaptation in all muscloskeletal system.

\section{References}

1. Babraj JA, Cuthbertson DJ, Smith K, Langberg H, Miller B, Krogsgaard MR, Kjaer M, Rennie MJ. Collagen synthesis in human musculoskeletal tissues and skin.

2. Am J Physiol Endocrinol Metab 289: E864E869, 2005.

3. Bonewald, L.F., Johnson, M.L. Osteocytes, mechanosensing and Wnt signaling.

4. Bone (2008) 42, 606-615.

5. Brink P.R., Ricotta J. and Christ G.J. Biophysical characteristics of gap junctions in vascular wall cells: implications for vascular biology and disease Braz J Med Biol Res (2000); 33(4): 415-422

6. Charles AC, Naus CC, Zhu D, et al: Intercellular calcium signaling via gap junctions in glioma cells. $J$ Cell Biol (1992)118:195-201 
7. Fritton SB and Sheldon Weinbaum S (2009): Fluid and Solute Transport in Bone: FlowInduced Mechanotransduction. Annu Rev Fluid Mech. (2009) 41: (1): 347-374.

8. Haudenschild AK, Hsieh AH, Kapila S, et al. Pressure and distortion regulate human mesenchymal stem cell gene expression. Ann Biomed Eng. (2009); 37(3):492-502.

9. Haus JM, Carrithers JA, Trappe SW, Trappe TA. Collagen, cross-linking, and advanced glycation end products in aging human skeletal muscle. J Appl Physiol 103: 2068-2076, 2007.

10. Henriksen DB, Alexandersen $P$, Bjarnason NH, Vilsboll T, Hartmann B, Henriksen EE, Byrjalsen I, Krarup T, Holst JJ, Christiansen C. Role of gastrointestinal hormones in postprandial reduction of bone resoprtion. J Bone Miner Res 18: 21802189, 2003.

11. Huijing PA. Muscle as a collagen fiber reinforced composite: a review of force transmission in muscle and whole limb. J Biomech 32: 329-345, 1999.

12. Kjaer M. Role of extracellular matrix in adaptation of tendon and skeletal muscle to mechanical loading. Physiol Rev 84: 649_ 698, 2004.

13. Koval M (2006). Pathways and control of connexin oligomerization. Trends Cell Biol 16, 159-166.

14. Laird DW (2006). Life cycle of connexins in health and disease. Biochem $\mathrm{J}$ 394, 527-543.

15. Langberg $H$, Rosendal $L$, and Kjaer $M$. Training-induced changes in peritendinous type I collagen turnover determined by microdialysis in humans. J Physiol 534: 297-302, 2001.

16. Lanyon LE. Osteocytes, strain detection, bone modeling and remodeling. Calcif Tissue Int 1993;53:S102-S106.

17. Rogers RS, Dawson AW, Wang Z, Thyfault JP, and Hinton1 PS (2011): Acute response of plasma markers of bone turnover to a single bout of resistance training or plyometrics. J Appl Physiol 111: 1353-1360, 2011

18. Scott JP, Sale C, Greeves JP, Casey A, Dutton J, Fraser WD. The role of exercise intensity in the bone metabolic response to an acute bout of weight-bearing exercise.

19. J Appl Physiol 110: 423-432, 2011

20.Shu Z, Xin-sheng C, Bing W. Mechanotransduction in osteoblast and osteocyte regulation Journal of Clinical Rehabilitative Tissue Engineering Research (2011); 24 : 4530 - 4535

21. Tatsumi S, Ishii K, Amizuka N, Li M, Kobayashi T, Kohno K, Ito M, Takeshita S, Ikeda K. Targeted ablation of osteocytes induces osteoporosis with defective mechanotransduction. Cell Metab (2007); 5: 464-475.

22. Wang $Y$ and Tian Z. Effects of Exercise for Collagen Fibers and the expression of Cx43,Cx45 on Rat's Ventrieular myocardium Journal of Beijing Sport University (2009); 6 6: 6. 
